\title{
Empirical research on implementation of full English teaching mode in the professional courses of the engineering doctoral students
}

\author{
Yunxia Zhang \& Li Li \\ College of Electronics and Information Engineering, Tongji University, Shanghai, China
}

\begin{abstract}
Under the historical background of increasingly close international exchanges, the international education trend becomes increasingly apparent. The doctoral students' education is the highest part of the higher education. The improvement of the doctoral students' ability to use English for academic research is increasingly important. Taking full English course of the doctoral students in the School of Control Science and Engineering of Tongji University as example, this paper explores the research and application of full English teaching mode, in order to provide reference for further research in this field.
\end{abstract}

Keywords: doctoral students; professional courses; full English teaching; teaching mode

\section{INTRODUCTION}

Driven by the economic globalization, the development of the higher education also presents a distinct international characteristic. The state has introduced a large number of policies to encourage the international exchanges, for example, to introduce overseas high-level talents, introduce advanced foreign educational resources, and increase efforts to support outstanding teachers and students (especially doctoral students) in the scientific research institutions to have an academic access to the first-class foreign universities. Meanwhile, the colleges and universities actively introduce foreign teachers, purchase foreign language searchable database resources, promote Sino-foreign cooperative projects, and set up bilingual / full English courses, in order to provide a platform for teachers and students to participate in the international exchanges and open up a new way.

Under the background of wide penetration of the concept of education internationalization, as the highest part of Chinese higher education, the education of the doctoral students should place the cultivation of the doctoral students' capacity for academic and scientific research and international communication skills in an important position. English is widely used in the international community, therefore, it is particularly important to have target to enhance cultivation of the doctoral students' ability to use English for academic research and writing, publishing academic viewpoints, and participating in academic discussion. In recent years, the Electronics and Information Engineering College has amended the requirements of publishing the academic papers on the doctoral students for several times, and given emphasis on publishing high-quality international journals and papers, thus undoubtedly putting forward higher requirements on the doctoral students' ability to use English. A good English literacy can effectively broaden the academic vision of the doctoral students, enhance their professional learning interests and abilities, increase their self-confidence in the academic exchanges, and allow them to have an access to the academic frontier as early as possible, enrich their innovative thinking, and devote to the cultivation of the international high-end professional talents.

\section{CURRENT SITUATION OF ENGLISH TEACHING FOR DOCTORAL STUDENTS}

In 2013, Tongji University put forward instructive advices for the amendment of the doctoral students training program, that is, to add an elective course Foreign Academic Exchanges in the compulsory courses, with a credit of 1 . In 2014, the Electronic and Information Engineering College formally adopted this proposal, and included it in the training program, thus providing a more direct basis for encouraging the international exchanges of the doctoral students. 
Table 1. Statistical table of enrollment situation of the doctoral students in the Electronics and Information Engineering College in recent three years

\begin{tabular}{|c|c|c|c|c|c|c|c|c|c|c|c|c|}
\hline \multirow{2}{*}{$\begin{array}{l}\text { Way of } \\
\text { enrollment }\end{array}$} & \multirow[b]{2}{*}{ Age } & \multirow{2}{*}{$\begin{array}{l}\text { Number } \\
\text { of people }\end{array}$} & \multicolumn{2}{|c|}{ Examinee source } & \multirow[b]{2}{*}{ Married } & \multirow{2}{*}{$\begin{array}{l}\text { In-service } \\
\text { personnel }\end{array}$} & \multicolumn{6}{|c|}{ To graduation date of the last education background } \\
\hline & & & Graduate & $\begin{array}{l}\text { On-the-job } \\
\text { personnel }\end{array}$ & & & $\begin{array}{l}\text { Current } \\
\text { year }\end{array}$ & $\begin{array}{l}1-2 \\
\text { years }\end{array}$ & $\begin{array}{l}3-5 \\
\text { years }\end{array}$ & $\begin{array}{l}6-10 \\
\text { years }\end{array}$ & $\begin{array}{l}11-15 \\
\text { years }\end{array}$ & $\begin{array}{l}16 \text { years } \\
\text { and above }\end{array}$ \\
\hline $\begin{array}{l}\text { Direct pursuit for } \\
\text { doctorate }\end{array}$ & $21-24$ & 49 & 49 & 0 & 0 & 0 & 49 & 0 & 0 & 0 & 0 & 0 \\
\hline $\begin{array}{l}\text { Master-doctor } \\
\text { continuous study }\end{array}$ & $22-30$ & 15 & 15 & 0 & 0 & 0 & 15 & 0 & 0 & 0 & 0 & 0 \\
\hline \multirow{5}{*}{$\begin{array}{l}\text { Common } \\
\text { enrollment }\end{array}$} & $24-30$ & 66 & 33 & 33 & 11 & 8 & 33 & 4 & 24 & 5 & 0 & 0 \\
\hline & $31-35$ & 28 & 0 & 28 & 23 & 15 & 0 & 2 & 5 & 15 & 6 & 0 \\
\hline & $36-40$ & 10 & 0 & 10 & 9 & 9 & 0 & 0 & 0 & 6 & 4 & 0 \\
\hline & $41-45$ & 4 & 0 & 4 & 4 & 4 & 0 & 1 & 0 & 1 & 0 & 2 \\
\hline & Subtotal & 108 & 33 & 75 & 47 & 36 & 33 & 7 & 29 & 27 & 10 & 2 \\
\hline Total & & 172 & 97 & 75 & 47 & 36 & 97 & 7 & 29 & 27 & 10 & 2 \\
\hline
\end{tabular}

However, the author organizes the postgraduates to participate in the international exchange program in recent two years. In view of the declaratory situation, the actual situation of the doctoral students' international exchanges is not optimistic. According to the interviews, many students reflect that they are not confident in their English proficiency, especially in the combination with English and major. To sum up, they are mainly the following two reasons:

(1) English proficiency of the doctoral students is generally low and uneven. There are roughly three ways of enrollment as a doctoral student: direct pursuit for doctorate, master-doctor continuous study and common enrollment. Direct pursuit for a doctorate means that the outstanding undergraduates are exempted from an examination and recommended to directly pursue a doctorate. These students generally have extended and strengthened their solid foundation in English since senior high school, with a strong proficiency in English, but who are lack in the combination with the profession. Master-doctor continuous study means that the outstanding postgraduates directly apply for doctoral study according to their own preferences after learning for a year and a half. Most of these students are engaged in the master-doctor continuous study, with a better foundation in English, and a strong plasticity, and accumulate some professional knowledge of English as a master. The common enrollment refers to entering school in a way of unified examination. The majority of these students are serving officers, who purpose a doctorate after working for several years. Due to a low usage rate of English in work, their English proficiency mastered as an undergraduate and a postgraduate suffers from great losses; in addition, they should not only complete their study and scientific research tasks, but also undertake a heavy responsibility for work and family, so they have less time to learn English, and it is difficult to improve their English proficiency. Thus, the doctoral students' education is the highest part of the higher education. However, compared with the undergraduate and postgraduate, English proficiency of the doctoral students is generally low. The author analyzes and sorts out the enrollment situation of the doctoral students in the Electronics and Information Engineering College in the past three years. As shown in Table 1, among 108 students with common enrollment, there are 75 on-the-job examinees, accounting for $69.4 \%$; 47 married examinees, accounting for $43.5 \%$; 36 in-service examinees, accounting for $33.3 \%$; 68 postgraduates who have graduated from school for more than three years, accounting for $63.0 \%$. These high proportions reflect the current situation of the doctoral students' learning. Combined with the foregoing analysis, this paper further explains the reason of low English proficiency of the doctoral students.

(2) English teaching for the doctoral students is detached from the profession. In recent years, the colleges and universities have done more reforms in English teaching for the doctoral students, and paid more attention to the cultivation of practical application ability, but they are still difficult to achieve combination with the profession. Taking Tongji University as an example, a compulsory course of public English is set up in the first semester of the doctoral students, with 2 credits and 72 credit hours, which is taught by the teachers of common required courses in College of Foreign Language. The course content is divided into three modules, namely, writing module (Essay Writing and Publishing, Advanced Writing), listening and speaking module (International Conference on English Communication, Advanced Spoken English) and reading module (Literature Reading and Translation, Advanced Reading), with a total of six sub-courses. The course provision has made a great progress on the cultivation of the doctoral students' ability to use English, but the professional English teachers are difficult to inspire and guide the students in a more specialized academic field even with a very solid foundation in English, so that many doctoral students are at loss when they are writing English papers, and some students even simply give up when they heard that they need to make an impromptu speech in the case of participation in an international conference. 


\section{ANALYSIS OF SIGNIFICANCE AND FEASI- BILITY OF IMPLEMENTATION OF FULL ENGLISH TEACHING FOR PROFESSIONAL COURCES OF THE DOCTORAL STUDENTS}

Cai Jigang, a Professor and Doctoral Tutor of School of Foreign Language of Fudan University points out that, if English teaching is just for laying a solid foundation in the language, rather than serving for the profession of the students, regardless of the strategic needs of the country, the students will fail to be engaged in the professional learning in English, or possess international communication skills and international competitiveness in their own professional field. That will be the biggest failure of English teaching ${ }^{[1]}$. The engineering doctoral students undertake a heavy burden on the engineering construction, information technology, environmental protection, bio-energy and other reform and construction of major projects, so they must possess a solid foundation in the academic research, and introduce advanced foreign technology and concept by virtue of their keen insight, thus serving for China's socialist construction. Given that English proficiency of the doctoral students is limited, and English teaching for the doctoral students is insufficient to meet the needs of the academic research of the students, the implementation of full English teaching for the professional courses will be a major reform in the doctoral students' education, which can not only dynamically combine English with the profession, but also fully mobilize the enthusiasm and participation of the doctoral students, increase their sensitivity to academic English, and enhance their ability and confidence in the use of English for academic activities. Of course, full English teaching involves in many aspects, such as teaching materials, teachers, methods and so on, which is a systematic project, so there is a need to increase investment to ensure the quality and effectiveness of full English teaching.

Viewing from the education policy, teaching staff and students' feedback in colleges and universities, the implementation of full English teaching for the professional courses of the doctoral students has a very favorable condition and foundation. Next, this paper gives an instruction by taking Tongji University as an example.

(1) The colleges and universities encourage the implementation of full English teaching in policy. With the accelerating process of internationalization of Tongji University, the international requirements of the course construction are increasingly urgent, and full foreign language teaching is an embodiment of such a requirement. During "the $12^{\text {th }}$ Five Year Plan", school builds a multilevel foreign language teaching course system by virtue of the traditional superior platform of the international exchange. In 2011, school officially launched bilingual teaching teams, and full English course construction work. By the end of 2013, school has funded 40 common bilingual teams, 20 senior bilingual teaching teams, 86 full foreign language courses, 14 full English course packages, 160 projects and 401 courses, including 234 full English course, accounting for $58 \%$ of the total number of courses, involving in the undergraduates, postgraduates and overseas students from 29 schools, thus basically building a multi-level and three-dimensional foreign language course system ${ }^{[2]}$. In the process of full English course construction, school attaches great importance to top-level design of the course system, and improves the overall strength of the full English teachers by means of "going out", "coming in" and cultivating by themselves", and also plays a role of supervision and students' evaluation of teaching, in order to ensure the quality of teaching. At the same time, the school also fully integrates with all resources to ensure the expenditure of the course construction. For example, 12,000 yuan of the course construction fee is funded for each full English course, and two times of credit hours' allowance (excluding normal credit hours' allowance) is offered to each course ${ }^{[3]}$, in order to promote the healthy development of the course construction.

(2) The colleges and universities possess high-level teachers, who have a good foundation in English. The internalization of the teaching staff plays an important dominant role in the cultivation of the internalization of the postgraduates ${ }^{[4]}$. The Electronics and Information Engineering College has two doctorate degree awarding units: Control Science and Engineering, Computer Science and Technology. Two doctor stations have a total of 129 full-time teachers, including 74 doctorial tutors. Among teaching staff, more than $99 \%$ of teachers have doctorate degree, $26 \%$ of teachers obtain doctorate degree from foreign universities, more than $70 \%$ of teachers have overseas exchange experience, and more than $70 \%$ of teachers are at less than 45 years old. With the well-known experts in this field as the leaders, and the middle-aged vigorous teachers as the backbone, a high-level teaching staff closely connected with teaching and scientific research has been formed, thus laying a solid foundation of teachers for the implementation of the full English teaching.

(3) The doctoral students generally support full English teaching. The doctoral students training program of the Electronics and Information Engineering College in 2014 stipulates that, the doctoral students need to at least acquire 13 credits, of which the professional degree course is 4 credits (generally two courses). The Control Science and Engineering opens up a total of 13 professional degree courses, of which one course is a cutting-edge course (compulsory course), nine courses are designed for the students who have a direct pursuit for a doctorate, and the remaining three courses include a full English course. The students need to take one from these three courses as an elective course. Viewing from the elective courses in autumn 2014 and spring 2015, 19 students 
take the full English course as an elective course, accounting for $52.8 \%$ of total professional courses. The students who take this course as an elective course generally reflect that the teaching effect is very good, and this course completely breaks an embarrassing situation of just recognizing some professional English words, but failing to know how to use English for the professional learning. According to the survey of the students who do not elect the full English course, $85 \%$ of students want to elect this course, but they worry about failure in exam due to their limited English proficiency. Thus, the students are very interested in and greatly support the full English course.

\section{EMPIRICAL RESEARCH OF FULL ENGLISH TEACHING MODE}

The full English teaching for the undergraduates and postgraduates has been widely concerned and implemented by major colleges and universities. However, the implementation of full English teaching for the professional courses of the doctoral students has not yet achieved in Chinese colleges and universities. The author enters the keywords, such as "doctorate", "professional course" and "full English" on three retrieval platforms - CNKI, WANFUN and VIP, but the search result is 0 . It is imperative to implement the full English teaching for the professional courses of the doctoral students, but there are many problems in the teachers, methods and resources. To solve the above problems is a progressive process, it requires to arranging reasonable teaching plan according to the actual situation of the teachers and students, and radiates to other professional courses with a certain course as a pilot based on a comprehensive analysis, and summarization of the teaching experience. Next, the author discusses the practice and application of the full English teaching mode by taking the full English professional course - System Analysis and Optimization of the doctoral students majored with the Control Science and Engineering as an example.

System Analysis and Optimization is a professional degree course established for the doctoral students majored with the Control Science and Engineering. The domestic and foreign well-known universities, such as the University of California, Purdue University, Tsinghua University, Northeastern University, Zhejiang University and other universities have set up similar courses. The teachers are our school's professors, doctorial tutors, young and middle-aged teaching staff, IEEE members and the teaching staff who have visited the University of Southern California.

(1) Teaching ideas and objectives

According to the doctoral students training objectives, the doctoral students should have the ability to "be proficient in using the first foreign language to carry out the academic research and academic exchange". To compensate for the fact that the current doctoral students are lack of the ability to use English for the academic research, this course has three construction objectives: in terms of the knowledge system, the students should have a systematic understanding of the principle and application based on the establishment of the modern optimal computing method, and master the basic theory of the system analysis and optimization, analysis and design methods, and commonly used implementation techniques; in terms of the ability training, the courses are matched up with the classroom discussion and great assignment, so that the students can not only have a solid theoretical knowledge, but also have the operational ability of the basic analysis, design and implementation; in terms of the comprehensive quality, the full English teaching will directly strengthen the students ability to use English for thinking creation and academic research. Based on the existing full English teaching achievements, there is a need to further improve the teaching methods and teaching means, and improve the teaching material systems and teaching materials, so as to construct this course as a full English course characterized by the first-class teaching staff, the first-class teaching content, and the first-class teaching methods and so on.

(2) Teaching content and teaching materials

It is adaptable to the school development and the quality of source of students. The construction of the course - Systems Analysis and Optimization is not only positioned to impart the basic professional knowledge, but also upgrades to the level of ability training and education of comprehensive quality. The teaching content comprehensively considers the development needs of the unity between the theory, practice and capacity, which requires the students to mastering commonly used modern optimal computing method and the ability to use this method to solve practical problems. The main credit hours of the course are arranged as follows: there is a total of 36 credit hours ( 2 credits), in which the theoretical course is 20 credit hours, literature reading is 12 credit hours, and classroom discussion is 4 credit hours. In terms of the allocation of the credit hours, the teachers' teaching accounts for $55 \%$, while the students' autonomous learning and discussion accounts for $45 \%$. This allocation program is beneficial to fully exert the students' initiative, so that the students have a lot of time for absorption, study and discussion.

A special teaching material is not stationary used for this course. However, the teachers produce the full English teaching courseware by reference of excellent original English teaching materials. The courseware covers a large number of English professional vocabularies and knowledge points in the Systems Analysis and Optimization, and also covers the theoretical teaching, practice teaching, extracurricular research and various teaching links, which can strengthen and link with the theoretical teaching and thinking ability of the foreign language; meanwhile, the adoption of 
the full English courseware can be better and faster to convert high-level scientific research resources into high-quality teaching resources, thus further improving the quality of teaching. To adhere to solve the problem of non-synchronous development between the classic principle teaching and the modern international information technology by reference of the original classic English textbook, it can not only improve the students proficiency in reading English professional literatures, but also is beneficial to training of the students ability of the international exchange.

(3) Teaching organizations and methods

The teaching organization of the course - Systems Analysis and Optimization has various forms, including the class, independent reading, practice by groups and classroom discussion. The teachers actively introduce the domestic and foreign advanced teaching mode, and convert the high-level teaching ideas into high-quality teaching resources. The full English teaching can promote teaching directly to be geared to international standards, and improve the international competitiveness of the students.

Advance organizer teaching method - the classroom teaching adopts the "advance organizer" teaching method. The method was proposed by Ausubel, an American cognitive and educational psychologist in the early $1960 \mathrm{~s}$. Its core idea is to present some of the introductory materials to the learners before learning new tasks, and the purpose is to explain, integrate and link up with the materials in the current learning tasks by the use of materials learned previously ${ }^{[5]}$. Due to the full English teaching, the students require more time to carrying out cognition and understanding of knowledge. Therefore, in the early period of the course teaching, to provide learning courseware, reference materials, typical cases and other introductory materials to the students can play a role in fastening and absorbing new learning content, and effectively promote to generate meaningful learning and maintain the significance of acquisition. The students have already had a certain understanding of the teaching content before class, so that they have more confidence and interest in classroom interaction in English, with a very good teaching effect.

Constructivism teaching method - constructivism believes that knowledge is not passively received by individuals through feelings or exchanges, but actively constructed by the cognitive subject through the interaction of the old and new experience ${ }^{[6]}$. In the independent reading link, the teachers recommend the mainstream journals to the students, and guide the students to understand the cutting edge of the field. The teachers do not specify the specific learning content, but the students should actively construct the new and old knowledge system, and discover, explore and solve problems, and write English reports according to their own interests and existing knowledge reserve. The teachers can judge and master the construction degree and level of knowledge through the content of the report, while the students can improve their ability of academic writing in English through the report.

Task-based approach - the students practice by groups based on the research direction, and adopts the modern optimization methods to solve the specific problems, and carry out the result show, experience exchange, discussion and analysis in the link of the classroom discussion. Of course, the teachers will arrange different tasks according to the difference in English proficiency of each group of students, and try to offer the opportunity to speak for every student, so that everyone is fully immersed in the English teaching environment. The way to use English for discussion of the professional knowledge can fully mobilize the subjective initiative of the students, and is also prone to make the teachers master the strengths and weaknesses of different students, in order to arrange the next round of more targeted teaching task.

(4) Teaching evaluation and assessment

The assessment method is converted from the form of traditional close-book exam to the form of great assignment to solve the problems, so that the learning focus of the students is really shifted from original mechanical memory of the learning content to the exploration and understanding of knowledge. At the end of the course, the students are required to conduct an oral report in English within a limited time, and they can illustrate the problems, express their viewpoints or put forward assumptions. A number of subject experts are invited to be as judges to provide on-site reviews and guidance. This method can develop the students' ability to use English to deliver academic viewpoints in a formal occasion, which is beneficial to the students' professional learning.

\section{CONCLUSION}

The implementation of the full English teaching for the professional courses of the doctoral students can effectively improve the doctoral students' ability to use English for the academic research. Taking the full English professional course - System Analysis and Optimization of the doctoral students majored with the Control Science and Engineering in Tongji University as an example, this paper explores the research and application of the full English teaching mode. Currently, the existing research in this field is not sufficient, which requires to being explored and discussed by the teaching staff.

\section{ACKNOWLEDGEMENT}

This paper is sponsored by the Shanghai Postgraduate Education and Innovation Project and the Postgraduate Fine (Core) Curriculum Construction Project of Tongji University. 


\section{REFERENCES}

[1] Cai Jigang. 2013. Example and its strategic significance of Chinese university's foreign language policy adjustment. Chinese University Teaching, (8): 12-13.

[2] Chen Yiyi. 2013. Practice and Exploration of Bilingual and Full English Course Construction in Tongji University: 2011-2013. Shanghai:Tongji University Press, pp.5.

[3] Tongji University. 2015. Financing management approach for bilingual teaching team and full English course construction project in Tongji University (tentative) [Z]. 2015-04-16.
[4] Liu Chengbo, Zhao Guoan, Fu Xueqi. 2013. To promote the postgraduate's international education to improve the quality of talent training - practice and exploration of the international training for the postgraduates in the School of Life Science of Jilin University. Modern Education Science, (3): 169.

[5] Chen Nailin. 2008. Applied research on Ausubel's meaningful reception learning theory in college English teaching. Nanjing: Nanjing Normal University.

[6] Chen Qi, Liu Rude. 2007. Contemporary Educational Psychology. Beijing: Beijing Normal University Press, pp.187-188. 